\title{
INTERVENÇÃO EDUCATIVA NO CONTROLE DE RESTOS EM UNIDADE DE ALIMENTAÇÃO E NUTRIÇÃO
}

\author{
Ana Paula Santos SILVA ${ }^{1}$ \\ Mariana Alves dos SANTOS ${ }^{2}$ \\ Mônica Glória Neumann SPINELLI ${ }^{3}$ \\ Andrea Carvalheiro Guerra MATIAS ${ }^{4}$ \\ Hellen Daniela de Sousa COELHO ${ }^{5}$
}

${ }^{1}$ Discente do curso de Nutrição da Universidade Paulista - UNIP. annapaulassilva @ gmail.com
${ }^{2}$ Discente do curso de Nutrição da Universidade Paulista - UNIP. marianaalvesdossantos@ @otmail.com

${ }^{3}$ Nutricionista, mestre e doutora em Saúde Pública (concentração em nutrição) pela Universidade de São Paulo. Docente do curso de Nutrição da Universidade Paulista - UNIP - Campus Cid. Universitária. monicaspi404@ gmail.com

${ }^{4}$ Nutricionista, mestre e doutora em Saúde Pública (concentração em nutrição) pela Universidade de São Paulo. Docente do curso de Nutrição da Universidade Paulista - UNIP -Campus Cid. Universitária. acgmatias@ gmail.com

${ }^{5}$ Nutricionista, mestre e doutora em Saúde Pública (concentração em nutrição) pela Universidade de São Paulo. Docente do curso de Nutrição da Universidade Paulista - UNIP -Campus Cid. Universitária. hellencoelho@gmail.com

Recebido em: 01/12/2015 - Aprovado em: 15/07/2016 - Disponibilizado em: 18/12/2016

\begin{abstract}
RESUMO
Na UAN, o desperdício é sinônimo de falta de qualidade e deve ser evitado através de um planejamento adequado.O resto, uma das formas de desperdício, é a quantidade de alimentos devolvida no prato ou bandeja pelo cliente, e deve ser avaliado não somente pelo lado econômico, mas pela da falta de interação com o cliente. O objetivo deste estudo foi avaliar a redução do desperdício de alimentos distribuídos aos clientes após intervençãoeducativa realizadana Semana Interna de Prevenção de Acidentes de Trabalho (SIPAT). Foi realizada a pesagem ecálculo per capita do resto antes e após a implantação da campanha contra o desperdício de alimentos. Na primeira etapa a média de per capita ficou em $50,7 \mathrm{~g}$ para alimentos em geral, e de $10,6 \mathrm{~g}$ para os alimentos proteicos, na segunda $36,4 \mathrm{~g}$ paraalimentos em geral e $6,3 \mathrm{~g}$ para os alimentos proteicos,representando uma redução média de $28,2 \%$ do primeiro e $40,5 \%$ do segundo. O trabalho evidencia que o trabalho de educação nutricional com os comensais deve ser realizado de forma contínua pelonutricionista para que o desperdício de alimentos possa ser controlado e as expectativas dos clientes sejam atendidas através da adequação dos cardápiosoferecidos.
\end{abstract}

Palavras-chave: Serviço de alimentação.Desperdício de alimentos. Restaurantes. Educação ambiental. Controle de qualidade.

\section{EDUCATIONAL INTERVENTION IN FOOD AND NUTRITION UNIT REMAINS CONTROL}

\begin{abstract}
In Food services, waste is synonymous of quality lack and should be avoided through proper planning. The leftovers, one of the forms of waste, is the amount of food in the dish or tray returned by the customer, and it must be evaluated not only by economic side, but by the lack of interaction with the customer. The objective of this study was to evaluate the reduction of food waste distributed to customers after educational intervention carried out in Internal Week of Occupational Accident Prevention. Weighing and per capita calculation was performed before and after the


implementation of the campaign against food waste. In the first stage the per capita average was $50,7 \mathrm{~g}$ for food in general, and 10.6g for protein feed, the second 36,4g for food in general and $6.3 \mathrm{~g}$ for protein feed, representing an average reduction $28.2 \%$ and $40.5 \%$ of the first second. The study shows that nutritional education work with diners should be carried out continuously by the nutritionist for food waste control and customer expectations can bereached adapting the menus offered.

Keywords: Food service. Food wastefulness.Restaurants.Environmental education. Quality control.

\section{INTRODUÇÃO}

O mercado de alimentação é dividido emsegmentos, sendo que os estabelecimentos que trabalham com produção e distribuição de alimentação para coletividades, atualmente recebem o nome de Unidades de Alimentação e Nutrição (UANs) (ABREU et al, 2013).

Sob o aspecto conceitual, segundo Cardoso et al. (2005), a Unidade de Alimentação e Nutrição (UAN) é considerada como a unidade de trabalho ou órgão de uma empresa que executa atividades relacionadas à alimentação e à nutrição, voltado para a alimentação adequada do ponto de vista nutricional e da qualidade higiênico sanitária, estabelecidos por legislação.

Dentre as atividades das UANS estão as de compras, recebimento, armazenamento de alimentos innatura, semiprocessados, e ou processados, para possibilitar a produção e distribuição das refeições para seus clientes(NONINO-BORGES, 2006).

O bom desempenho da UAN é resultante do planejamento da sequência e sucessão de ações voltadas aos objetivos de produção das refeições (MÜLLER, 2008), de modo a apresentar eficiência nos resultados e evitar desperdícios, podendo ser controlado por meio de indicadores.
O desperdício envolve diversos tipos de perdas, tais como, alimentos que não são distribuídos, preparações prontas que não chegam a ser servidas e/ou vendidas e ainda as que restam nos pratos dos clientes (CASTRO, 2002).

Na UAN, o desperdício é sinônimo de falta de qualidade e deve ser evitado através de um planejamento adequado, para que não haja excessos de produção e nemrestos. Deve ser realizado por um profissional especializado, com capacidade para prever o rendimento final de cada alimento, levando em consideração as preparações mais consumidas e o per capita (ABREU et al., 2013).

São considerados restosos alimentos devolvidos no prato ou bandeja pelo cliente.Esses são indícios de desperdício no restaurante e devem ser avaliados não somente pelo lado econômico, mas pela da falta de interação com o cliente(ABREU et al., 2013).

Para Corrêa et al. (2006), o objetivo do controle de resto é acertar o porcionamento na distribuição e a aceitação do cardápio.

Por meio da identificação das perdas, é possível tomar medidas corretivas e ações em favor da melhoria contínua e aprimorada de resultados (RIBEIRO, 2002). É de extrema 
importância para todas as empresas aprimorar a eficiência, no intuito de diminuir, eliminar ou prevenir as perdas, o que reflete diretamente nos números finais (DENNIS, 2008).

Segundo Ribeiro (2002), cada alimento perdido em virtude de erros em processos, planejamento ou consumo inadequado dos clientes, torna-se um grande prejuízo no controle de custos de matéria prima. Para isso, a utilização de ferramentas que evidenciem as perdas existentes, bem como a medida das mesmas, e decorrentes intervenções, são imprescindíveis para a lucratividade da empresa e satisfação do cliente atendido.

Deste modo, o objetivo do presente estudo, foi quantificar os restos e avaliar a redução do desperdício de alimentos distribuídos aos clientes, após intervenção educativa.

\section{MATERIAIS E MÉTODOS}

Estapesquisa foi realizada em duas etapas, entremeadas por uma intervenção educativa, na refeição almoçode uma unidade de alimentação, localizada na zona Oeste da cidade de São Paulo.

A unidade serve diariamente durante o almoço aproximadamente 550 refeições, em sistema autosserviço, com utilização de bandejas lisas e pratos. O cardápio oferecido é bastante diversificado e de nível médio. É composto por 5 tipos de saladas, 2 de guarnição, 2 de preparações proteicas (prato principal), 2 tipos de frutas, 1 doce, gelatina, além de arroz branco, integral e feijão (variando o tipo conforme o cardápio).

Na etapa 1 (pré intervenção), foram pesadosos restosdurantedez diase na etapa 2durante oito dias (pós intervenção).

Também foi avaliado o volume aproximado de restos por meio da observação do número de sacos de 100L descartados diariamente.

A intervenção educativa foi realizada durante cinco dias, durante a SIPAT (Semana Interna de Prevenção de Acidentes de Trabalho), com o objetivo de reduziro desperdício. Foi escolhida esta semana pelo seu cunho educativo e de motivação dos funcionários.Para esta foi preparada uma sensibilização por meio de cartaz fixado no refeitório, com os valores de resto pesados na primeira etapa, e fotos de desperdício nos pratos. Foi montada, também, uma plataforma na qual foram empilhados, diariamente, alimentos in natura (arroz, feijão e outros), com peso correspondente ao dos restos da véspera para representar visualmente a quantidade desperdiçada na etapa 1 .

Durante o momento da devolução, nesta semana, os clientes foram questionados sobre os motivos que determinaram os restos.

Nos dias de coleta, foram separados dois recipientes de lixo (100 litros), um para 
acondicionamento dos restos dos alimentos (arroz, feijão, guarnição, salada e sobremesa) e outro apenas para os das preparações proteicas. Para que não houvesse interferência no peso dos restos foi colocado um terceiro recipiente para a coleta de cascas, ossos e descartáveis. Após o término do almoço, os sacos foram pesados, em uma balança mecânica industrial de coluna.

As preparaçõesproteicas (prato principal) foram pesadasà parte, uma vez que para a unidade de alimentação, em relação aos itens alimentícios, estassão responsáveis pelo maior investimento.

A segunda etapa, para verificar o efeito da campanha, seguiu o mesmo procedimento de coleta de dados.
Para a análise dos dados referentes aos restos dos pratos dos clientes, foi utilizada a seguinte fórmula:

per capita do resto $=$ peso do resto $/$ número de refeições servidas (ABREU et al, 2013).

Os dados foram tabulados no programa Microsoft Excel 2010 e os resultados foram expressos em tabelas.

A pesquisa seguiu todos os procedimentos éticos e recebeu a aprovação do comitê de ética - CAAE 43235615.1 .0000 .5512 .

\section{RESULTADOS E DISCUSSÃO}

Tabela 1 - Restos per capita na etapa 1 - pré-intervenção. São Paulo, 2015.

\begin{tabular}{ccccc}
\hline Dia & $\mathbf{N}^{\mathbf{0}}$ Refeições & \multicolumn{2}{c}{ Restos per capita (g/dia) } \\
\hline & \multicolumn{5}{c}{ Sem preparação proteica } & Preparação proteica & Total \\
\hline 1 & 611 & 56,5 & 8,7 & 65,2 \\
2 & 539 & 82,4 & 16,5 & 98,9 \\
3 & 575 & 38,6 & 10,4 & 49,0 \\
4 & 581 & 45,4 & 6,5 & 51,9 \\
5 & 560 & 53,9 & 8,6 & 62,5 \\
6 & 594 & 57,1 & 8,4 & 65,5 \\
7 & 576 & 56,6 & 12,0 & 68,6 \\
8 & 602 & 35,5 & 9,1 & 44,6 \\
9 & 560 & 42,3 & 5,5 & 47,8 \\
10 & 576 & 38,9 & 20,4 & 59,3 \\
\hline Média & 577 & 50,7 & 10,6 & 61,3 \\
Desvio padrão & & & & \\
\hline
\end{tabular}


$\mathrm{Na}$ primeira etapa deste estudo, em que segundo dados da própria unidade, a média per capita de alimentos distribuídos foi de $440 \mathrm{~g}$, pode-se observar na Tabela 1 que houve uma grande variação per capita do resto entre 44,6g e 98,9g, representando entre 10 e $22,5 \%$ da quantidade servida. Esse fato pode ser também observado com os restos das preparações proteicas que variaram de $6,5 \mathrm{~g}$ a $20,4 \mathrm{~g}$, equivalente a uma variação de 1,5 a $4,6 \%$ do total.

Váriosfatores estão relacionados ao valor do resto: a falta de conscientização do comensal, que se serve de quantidades superiores às quais consegue consumir, aceitação do prato pelo cliente, tempo disponível para o consumo, a qualidade da preparação (salgada, crua, gordurosa, dura, queimada), porcionamento inadequado das preparações (impossibilidade de opção por porções menores), falta de identificação das preparações induzindo ao engano, utensílios de servir inadequados (VAZ, 2006)

Com relação ao volume de lixo gerado, verificou-se que, em média, diariamente, descartaram-se 100L de resto das preparaçõesproteicas e 400L das demais, correspondendo a mais de $10.000 \mathrm{~L} / \mathrm{mês}$ direcionados ao aterro sanitário.
Para Maragno, Trombin e Viana (2007), os resíduos orgânicos são responsáveis pela principal fonte de impactos ambientais, pois o chorume gerado na decomposição provoca grande quantidade de matéria orgânica, microrganismos, metais pesados e outras substâncias danosas ao meio ambiente.

A média dos restos de alimentos e dos pratos proteicos,se somados,representaria uma média de $61,4 \mathrm{~g}$ por cliente, ou seja, $14 \%$ do alimento servido no prato do cliente. Não há um consenso sobre a quantidade de restos aceitável embora, por se tratar de um restaurante com distribuição por autosserviço, seria de se esperar um resultado muito inferior, uma vez que o cliente pode optar tanto pelas preparações de seu agrado e hábito quanto pela quantidade a ser servida.Resultado semelhante de restos foi encontrado por Bicalho e Lima (2013) e Machado et al. (2012). Para Abreu et al. (2013) o resto deve tender ao zero, caso os processos sejam controlados e haja uma interação positiva com o cliente. Para Vaz (2006) restos entre 2 e $5 \%$ da quantidade servida (15 a 45g/ pessoa), não são razoáveis, mas podem ser admitidos como normais. 
Tabela 2 - Restos per capita na etapa 2 - pós intervenção. São Paulo, 2015.

\begin{tabular}{ccccc}
\hline Dia & $\mathbf{N}^{\mathbf{0}}$ Refeições & \multicolumn{3}{c}{ Restos per capita (g/dia) } \\
\hline & & Sem preparação proteica & Preparação proteica & Total \\
& & & & \\
1 & 630 & 47,3 & 10,9 & \\
2 & 517 & 37,7 & 8,6 & 45,0 \\
3 & 571 & 51,3 & 9,1 & 59,9 \\
4 & 618 & 40,1 & 7,5 & 49,2 \\
5 & 534 & 42,9 & 12,1 & 50,4 \\
6 & 578 & 43,7 & 2,3 & 55,8 \\
7 & 607 & 59,3 & 4,9 & 61,6 \\
8 & 597 & 41,9 & 7,9 & 46,8 \\
\hline Média & 582 & 45,5 & 3,1 & 53,4 \\
\hline Desvio padrão & \multicolumn{5}{c}{} \\
\hline
\end{tabular}

Pode-se perceber que, mesmo após a intervenção educativa, ainda houve uma variação considerável na quantidade de desperdício nesta etapa da pesquisa e que a quantidade de restos, embora menor, continuou alta (Tabela 2).Antes da intervenção a média de resto apresentava-se $61,3 \mathrm{~g}$ e após a campanha passou a ser $53,4 \mathrm{~g}$ diferença de 12,9\%. Segundo Abreu et al. (2013) os restos podem ser decorrentes da quantidade excessiva proporcionada pelo cliente ou pelo funcionário da UPR e também resultado de preparações mal elaboradas, essas duas últimas consequência de falta de preparo dos colaboradores.

Para pratos proteicos a média foi de $10,6 \mathrm{~g}$ para $7,9 \mathrm{~g}$, com redução de $40,5 \%$. Os restos dos pratos proteicos representaram $20,9 \%$ dos demais restos antes da intervenção passando para $17,4 \%$ após a campanha.

No total, computados os restos dos pratos proteicos e dos demais se observou uma redução de12,9\%.

Esses valores, se computados em um mês de 22 dias úteis, equivaleriam, em média, a aproximadamente $778 \mathrm{Kg}$ de alimentos, dos quais $135 \mathrm{Kg}$ de preparações proteicas,equivalendo a 1768 refeições desperdiçadas no período pré intervenção, e no período pós intervenção $684 \mathrm{Kg}$ e 1554 refeições, refletindo em um grande valor econômico desperdiçado pela unidade..

A literatura apresenta alguns estudos com redução positiva dos restos após campanhas, comono realizado porBicalho e Lima (2013), com redução de 25,6\%, Machado et al. (2012) com redução de 9,2\%, Corrêa(2006), em que houve praticamente 92\% de diminuição de restos após a intervenção, e no de Paiva et al. (2005) realizado em uma unidade hospitalar, embora mostre que nem todostiveram o mesmo efeito, como no de Lechner e Giovanoni (2012), que não apresentou variação.

Campanhas dessa natureza devem estar em consonância com a filosofia ambiental da empresa, uma vez que caso isso não ocorra, a tentativa de redução do desperdício será encarada pelo cliente como uma forma de restrição econômica à custa da 
redução dos alimentos servidos (ABREU et al., 2013), cabendo, portanto, a cada serviço de nutrição escolher os seus indicadores, que devem ser compatíveis com seus objetivos (ISOSAKI; NAKASATO, 2009).

Para Martins et al. (2006), quantidades significativas de restos de alimentos justificam a importância do gerenciamento do controle de desperdício, pela sua repercussão ética e econômica, pois estes gastos poderiam ser direcionados para ações cidadãs, além da preocupação com a responsabilidade ambiental.

Sayur e Pinto (2009) relatam que o atendimento pelo sistema autosserviço total, pode contribuir para o aumento dos restos por induzir os comensais a se servirem de uma quantidade maior do que a de costume.

Assim, compete ao nutricionista responsável pela unidade promover educação nutricional à sua coletividade, implantar e supervisionar programas de controle de desperdício, e promover atitudes de

\section{CONCLUSÃO}

O controle de restos em unidades de alimentação e nutrição deve ser um instrumento utilizado tanto para controle de desperdício quanto para custo e qualidade da refeição servida, promovendo interação entre os clientes. consciência social e ambiental junto aos seus clientes (CFN,2005).

Faz-se necessário quea unidade realize ações contra o desperdício continuamente para que essa média reduza progressivamente, como também sugerido por Moura et al. (2010) e Augustini et al. (2008).

Sugere-se, também, que a unidade possibiliteao cliente dese servir novamente, uma vez que essa atitude não é permitida, o quefaz com que essesesirva de grandes quantidades gerando maior desperdício. Essa condição também foi observada Augustini et al. (2008), mostrando que o fato não é incomum em restaurantes institucionais.

É importante que o cliente se conscientize quanto à importância de diminuir o resto alimentar, uma vez que este gera um impacto ambiental e econômico para a unidade.

A campanha educacional é importante como elemento de sensibilização dos clientes, porém é necessário que a unidade avalie continuamente a satisfação em relação ao cardápio, bem como seus processos para identificar possíveis falhas que gerem uma maior quantidadede restos e crie parâmetros e mecanismos que possibilitem adequação de distorções.

Para ações contra o desperdício é necessário, também, definir o perfil de 
clientela atendida e trabalhar em conjunto para obter resultados satisfatórios.

Desta forma por meio de atitudes contínuas do nutricionista e de sua equipe será

\section{REFERÊNCIAS}

ABREU, E.S.; SPINELLI,M.G.N.;PINTO, A.M.S. Gestão de unidades de alimentação e nutrição: um modo de fazer. Metha, 2013.

AUGUSTINI, V.C.M. Avaliação do índice de resto-ingesta e sobras em unidade de alimentação e nutrição (UAN) de uma empresa metalúrgica na cidade de Piracicaba/SP. Simbio-Logias, v.1,n.1, p.99110,2008 .

BICALHO, A. H.; LIMA, V. O. B. Redução do desperdício em uma Unidade de Alimentação e Nutrição. Nutrire, v. 38, n. 3, p. 269-277, 2013.

CARDOSO, R.C.V.; SOUZA, E.V.A.; SANTOS, P.Q.; Unidades de alimentação e nutrição nos campi da Universidade Federal da Bahia: um estudo sob a perspectiva do alimento seguro. Revista de Nutrição, v. 18, n. 5, p. 670, set./out. 2005.

CASTRO, M.H.C.A. Fatores determinantes de desperdício de alimentos no Brasil: Diagnóstico da situação. 2002. 93p. Monografia (Especialização em Gestão de Qualidade em Serviços de Alimentação) Universidade Estadual do Ceará, Fortaleza, 2002.

CFN - CONSELHO FEDERAL DE NUTRICIONISTAS.RESOLUÇÃO CFN $\mathbf{N}^{\circ} \mathbf{3 8 0} / \mathbf{2 0 0 5}$. Dispõe sobre a definição das áreas de atuação do nutricionista e suas atribuições, estabelece parâmetros numéricos de referência, por área de atuação, e dá outras providências. Disponível em:

http://www.cfn.org.br/novosite/pdf/res/2005/r es380.pdf. Acesso em 23/03/2015. possível obter resultados positivos, atendendo assim as expectativas da empresa para a qual é prestado o serviço e aos seus clientes.

CORRÊA, T.A. et al. Índice de resto-ingestão antes e durante a campanha contra o desperdício, em uma unidade de alimentação e nutrição. Revista Higiene Alimentar, Campinas, v. 20, n. 140,p.64-83, abril, 2006.

PASCAL, D. Produção Lean Simplificada. Porto Alegre: Bookman, 2008. 192 p.

GOMES, G.S.; JORGE, M.N.;Avaliação do índice de resto-ingestão e sobras em uma unidade produtora de refeição comercial em Ipatinga-MG. Nutris Gerais, Ipatinga, ano 6, n. 10, fev./jul. 2012. Disponível em: $<$ http://www.unilestemg.br /nutrirgerais/downloads/artigos/volume6/edic ao-10/avaliacao-do-indice-de-resto -ingestaoe-sobras-em-uma-unidade-produtora-derefeicao-comercial.pdf>. Acesso em: 26 março 2015.

ISOSAKI,M.; NAKASATO, M. Gestão de serviço de nutrição hospitalar. Rio de Janeiro: Elsevier, 2009. 360 p.

LECHNER, A.;GIOVANONI,A. Avaliação do resto-ingesta em uma unidade de alimentação no Vale do Taquari - RS.

Revista Destaques Acadêmicos, v. 4, n. 3, p.79-83,2012.

MACHADO,C.C.B; MENDES,C.K.; SOUZA,P.G.;MARTINS,K.S.;SILVA,C.C. Avaliação do índice de restoingesta de uma unidade de alimentação e nutrição institucional de Anápolis - GO. Ensaios e Ciência: ciências biológicas, agrárias e da saúde.v.16,n.6,p.151-162,2012.

MARAGNO, E.S.; TROMBIN, D.F.;VIANA, E. O uso da serragem no processo da mini 
compostagem. Engenharia Sanitária e

Ambiental, v.12, p. 355-360, 2007.

MARTINS, M. T. S; EPSTEIN, M.;

OLIVEIRA, D. R. M. Parâmetros de controle e/ou monitoramento da qualidade do serviço empregado em uma unidade de alimentação e nutrição. Revista Higiene Alimentar, São

Paulo, v. 20, n. 142, p.64-71, set. 2006.

MOURA, P.N.; HONAISER, A.;

BOLOGNINI, M.C.M. Avaliação do índice de resto ingestão e sobras em uma unidade de alimentação e nutrição (U.A.N.) do colégio agrícola de Guarapuava (PR). Revista Salus Guarapuava, n. 1, jan./jun. 2009. Disponível em:

$<$ http://revistas.unicentro.br/index.php/salus/a rticle/view/702/1158>. Acesso em: 15 março 2015.

MÜLLER, P.C. Avaliação do desperdício de alimentos na distribuição do almoço servido para os funcionários de um hospital público de Porto Alegre-RS. Porto Alegre: UFRGSA, 2008. Disponível em: http://www.lume.ufrgs.br/handle/10183/1655 $\underline{6}$

NONINO-BORGES, C. B, et al. Desperdício de alimentos intra-hospitalar. Revista de Nutrição, Campinas, v.19, n.3, p.349 - 356 Maio/Junho 2006.

PAIVA, D.C.S.; NASCIMENTO, J.C.; CABRAL, B.E. M.; FÉLIX, A. C. F.; LOPES, M. S.; ESTEVAM, E. Avaliação do índice de resto-ingestão em uma unidade de alimentação e nutrição de um hospital oncológico após alteração no sistema de distribuição e controle de sobras. Revista Científica da Faminas, v. 11, n. 1, p. 45-54, 2015.

RIBEIRO, C.S.G. Análise de Perdas em Unidades de Alimentação e Nutrição (UANS) industriais: estudo de caso em Restaurantes Industriais, Florianópolis: UFSC, 2002. Disponível em:

https://repositorio.ufsc.br/bitstream/handle/12 3456789/82680/191792.pdf? sequence $=1$
SAYUR, J.; PINTO, A. M. S. Avaliação do resto alimentar em uma Unidade de Alimentação e Nutrição. RevNutr Pauta, p. 62-65, jul./ago. 2009.

SILVA, A.M.; SILVA, C. P.; PESSINA, E.L. Avaliação do índice de resto ingesta após campanha de conscientização dos clientes contra o desperdício de alimentos em um serviço de alimentação hospitalar. SímbioLogias, Botucatu, ano 3, n. 4, jun. 2010. Disponível em: <http://www.ibb.unesp.br/Home/Departament os/Educacao/Simbio-

logias/Avaliacao_indice_de_resto_ingesta_ap os_campanha_conscienti.pdf $>$. Acesso em: 23 março 2015.

VAZ, C.S. Restaurantes - controlando custos e aumentando lucros. LGE Editora Ltda. Brasília, 2006.196 p. 